\title{
Editorial: Freshwater Ecosystems in Arid and Semiarid Zones Facing Multiple Stressors: Human Disturbances, Climate Change, and Dryland River Conservation
}

\author{
Eugenia López-López * \\ Laboratorio de Evaluacion de la Salud de los Ecosistemas Acuaticos, Escuela Nacional de Ciencias Biologicas, Instituto Politecnico \\ Nacional, Ciudad de México, Mexico.
}

Keywords: dryland rivers, stressors, invader species, river corridors, bioindication and biomonitoring, conservation

Editorial on the Research Topic

Freshwater Ecosystems in Arid and Semiarid Zones Facing Multiple Stressors: Human Disturbances, Climate Change, and Dryland River Conservation

Arid zones, which cover more than $45 \%$ of the Earth's surface (Bastin et al., 2017), are home to high species biodiversity. These dry landscapes receive scarce volumes of rain that are highly variable in space and time (Free et al., 2013). As a result, runoff and drainage systems that delineate the arid or semi-arid zones are inhabited by biota specially adapted to survive under water stress (Davis et al., 2013). These environments sustain water flows that can be perennial, with changes in their water level, as well as intermittent rivers under extreme conditions, which represent one of the largest environmental filters for aquatic biota; thus, the remnant waterbodies of dryland rivers represent refuges for aquatic biota (Sheldon et al., 2010). In addition, various arid and semi-arid areas have been considered threatened biodiversity hotspots (Mittermeier et al., 2011) because of multiple stressors that jeopardize their high diversity. Stressors include those directly caused by man and those related to climate change, both inducing the decline of populations in these ecosystems.

This special volume presents comprehensive analyses of dryland rivers, particularly in some of the least studied regions of the world and that currently face multiple stressors, however, an in-depth understanding of their biodiversity and functioning is still missing.

This Research Topic provides an overview and specific case studies of research on dryland rivers, with the following objectives: 1) increase our understanding of the processes that take place in natural and human-impacted dryland rivers; 2) describe the available tools to assess the effects of multiple stressors on dryland rivers; 3) advance current knowledge of the biodiversity and adaptation mechanisms of aquatic biota in dryland rivers; and 4) review some of the conservation and restoration strategies that have been put forward for these ecosystems. This Research Topic also addresses interdisciplinary environmental research on dryland rivers and their restoration and conservation. The scope includes:

Received: 12 November 2021 Accepted: 25 November 2021 Published: 09 December 2021

Citation:

López-López E (2021) Editorial: Freshwater Ecosystems in Arid and

Semiarid Zones Facing Multiple Stressors: Human Disturbances, Climate Change, and Dryland River Conservation.

Front. Environ. Sci. 9:814225. doi: 10.3389/fenvs.2021.814225

\section{SPATIO-TEMPORAL VARIABILITY ASSESSMENT OF HYDROLOGY, WATER QUALITY, AND AQUATIC BIOTA, AND IDENTIFICATION OF THE KEY DRIVERS OF DRYLAND COMMUNITY STRUCTURE AND ECOSYSTEM PROCESSES}

In Costa Rica, Guanacaste is characterized by an almost total absence of rain during the dry season, causing the dry-up of rivers, while in the wet season, many rivers overflow as a result of heavy rains. 
Bioindicator macroinvertebrate assemblages have shown wide variations in water quality related to management conditions. Predators and scrapers are dominants instead of shredders, contrasting with the "river continuum" concept. Despite the changes in land use, an extraordinary biodiversity was observed related to the ancient origin of tropical rain forests in Central America (Kohlmann et al.).

\section{ADAPTATION MECHANISMS OF AQUATIC BIOTA TO DRYLAND RIVER CONDITIONS}

Dryland rivers are facing the effects of biological invasions. The Argentinian Patagonia has been invaded by the exotic clam Corbicula fluminea. Labaut et al. found a homogeneous assemblage of aquatic macroinvertebrates. $\beta$ diversity was impacted in the invaded sites, while $\alpha$ diversity was unaffected in more productive sites. Gastropods, bivalves, Coleoptera, and Trichoptera were adversely affected; however, Ephemeroptera probably obtain extra food from the bioturbation activities of $C$. fluminea.

\section{INTEGRATION OF LONG-TERM MONITORING DATA DOCUMENTING THE EFFECTS OF CLIMATE CHANGE ON DRYLAND RIVERS}

The effect of climate change over the past 40 years was studied in the Tehuacán-Cuicatlán Biosphere Reserve, Mexico, by SedenoDiaz and Lopez-Lopez, who compared endogenous versus exogenous rivers. Normalized temperature anomalies and the Global Warming Index suggest an increasing trend in these parameters. The Vegetation Index (NDVI), Normalized Difference Water Index (NDWI), and Normalized Difference Drought Index (NDDI) are indicators of climate change. Both river corridors showed resilience strategies to face climate change.

The dryland rivers of Peru (displaying a wide altitudinal range $0-3,831 \mathrm{~m}$. asl) are still in early stages of biodiversity research. These dryland rivers represent an opportunity to study biological adaptations. Arana et al. integrated a research period (1992-2020) focused on aquatic macroinvertebrates inhabiting dryland waterbodies. Relevant topics studied include bioindication, biodiversity, and distribution. The influence of hydrometeorological forcings (El Niño and La Niña) represent a future area of research in Peruvian dryland rivers.

Kaczmareck et al. studied the occurrence of freshwater insect assemblages and environmental variables in northwest Africa, analyzing the effects of climate change and human disturbances on richness and functional traits of insect assemblages. Family richness was lower in arid zones relative to temperate areas. Almost one-third of the temperate areas are predicted to become arid by the end of the century; consequently, the presence and abundance of insect families are likely to decrease, particularly those adapted to temperate environments. Traits such as small body size, aerial dispersal, and air breathing favor survival in arid climates.

\section{NOVEL APPROACHES FOR THE INTEGRATION OF DIFFERENT STRESSORS (CHANGES OF LAND USE, CLIMATE CHANGE, AND ENVIRONMENTAL CONSEQUENCES) ACROSS MULTIPLE SITES USING STATISTICAL AND MODELLING TOOLS}

Marshall et al. combined remote-sensed mapping of waterholes that remained over an extreme drought event with the assessment of in-stream barriers to estimate the constraints on fish to move and repopulate the study area after the drought. This investigation is a model for assessing and prioritizing the management of fish population viability facing drought and fragmentation risks in non-perennial river settings.

\section{SUSTAINABLE USE, RESTORATION, AND CONSERVATION STRATEGIES FOR DRYLAND RIVERS}

Relevant conservation efforts are currently ongoing in dryland rivers of the Southern Africa and the Mediterranean Africa in North Africa. Khelifa et al. studied Odonate assemblages in dryland rivers flowing in both areas and estimated the dragonfly biotic index, associating it with climate and anthropogenic changes. The authors estimated previous and future changes in temperature and precipitation considering three scenarios.

Separately, the Andean Altiplano (altitude $>3,600 \mathrm{~m}$. asl), with a unique diversity of aquatic ecosystems, harbors two salt flats that were studied by Heine-Fuster et al. Authors compared diatom guilds from a functional perspective, in addition to the potential anthropic impact on their community structures. Motile diatoms are a key guild for maintaining the diatom community. The most heterogeneous community was observed in Ascotán, with the highest diversity probably related to human activities; these findings highlight the need to reexamine the effectiveness of past conservation activities.

\section{AUTHOR CONTRIBUTIONS}

EL-L conceived the idea reviewed and contributed to the final version of the editorial. 


\section{REFERENCES}

Bastin, J.-F., Berrahmouni, N., Grainger, A., Maniatis, D., Mollicone, D., Moore, R., et al. (2017). The Extent of forest in Dryland Biomes. Science 356, 635-638. doi:10.1126/science.aam6527

Davis, J., Pavlova, A., Thompson, R., and Sunnucks, P. (2013). Evolutionary Refugia and Ecological Refuges: Key Concepts for Conserving Australian Arid Zone Freshwater Biodiversity under Climate Change. Glob. Change Biol. 19 (7), 1970-1984. doi:10.1111/gcb.12203

Free, C. L., Baxter, G. S., Dickman, C. R., and Leung, L. K. P. (2013). Resource Pulses in Desert River Habitats: Productivity-Biodiversity Hotspots, or Mirages? PLoS ONE 8 (10), e72690. doi:10.1371/journal.pone.0072690

Mittermeier, R. A., Turner, W. R., Larsen, F. W., Brooks, T. M., and Gascon, C. (2011). "Global Biodiversity Conservation: The Critical Role of Hotspots," in Biodiversity Hotspots. Editors F. Zachos, and J. Habel (Berlin/Heidelberg, Germany: Springer), 3-22. doi:10.1007/978-3-642-20992-5_1

Sheldon, F., Bunn, S. E., Hughes, J. M., Arthington, A. H., Balcombe, S. R., and Fellows, C. S. (2010). Ecological Roles and Threats to Aquatic Refugia in Arid
Landscapes: Dryland River Waterholes. Mar. Freshw. Res. 61, 885-895. doi:10.1071/mf09239

Conflict of Interest: The author declares that the research was conducted in the absence of any commercial or financial relationships that could be construed as a potential conflict of interest.

Publisher's Note: All claims expressed in this article are solely those of the authors and do not necessarily represent those of their affiliated organizations, or those of the publisher, the editors and the reviewers. Any product that may be evaluated in this article, or claim that may be made by its manufacturer, is not guaranteed or endorsed by the publisher.

Copyright $\odot 2021$ López-López. This is an open-access article distributed under the terms of the Creative Commons Attribution License (CC BY). The use, distribution or reproduction in other forums is permitted, provided the original author(s) and the copyright owner(s) are credited and that the original publication in this journal is cited, in accordance with accepted academic practice. No use, distribution or reproduction is permitted which does not comply with these terms. 